الهجلة الدولية لنشر البحوث والدراسات International Journal of Research and Studies Publishing ISSN: 2709-7064

\title{
المثل الأخلاقي وفن المديح
}

\section{Moral parable and the art of compliment}

الباحثة/ لطيفة إبراهيم الرشيدي

ماجستير لغة عربية، كلية العلوم والدراسات الانسانية، جامعة شقر اء، المملكة العربية السعودية

Email: Lalrashyde@su.edu.sa

\section{الملخص:}

يهدف هذا البحث إلى تسليط الضوء على مفهوم الأخلاق من منظور غربي وفلسفي و إسلامي ومدى تفاوت الأر اء في تحديد مفهوم القيم الأخلاقية ومصدر ها حيث يرى الغرب بأن الأخلاق هي نظرة متغيرة نسبية

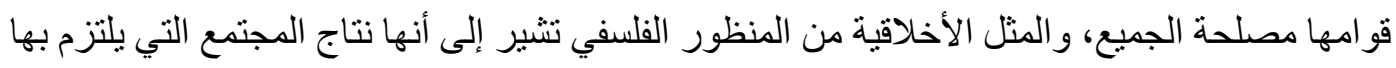
الأفر ادو أحكامهم العقلية التي تصدر منهم، ومن الناحية الإسلامية ينظر إلى المثل الأخلاقية بأنها علاقة الفرد بربه و المجتمع، وجاءت هذه الدراسة ايضا في الحديث عن أهم الأغر اض الثعرية وهو المديح ومفهومه و علاقته بحياة الثاعر وقبيلته.

اشتملت هذه الدر اسة على مقدمة وفصل يتكون مبحثين وخاتمة تليها المصادر و المر اجع، ومن أهم النتائج التي توصلت الباحثة إليها أن المثل الأخلاقية كانت موضع جدل وخلاف بين النقاد العرب و القدامى ولى ونى و المحدثين وشعر المديح الذي قيل بغرض التكسب أكسب الثعر الوانا جديدة واهتمام الثاعر في التألق

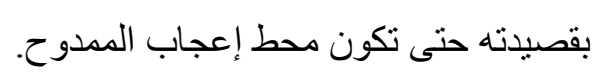
الكلمات المفتاحية: الاخلاق، قصيدة، أبي تمام، العرب، الادب، المدح. 


\title{
Moral parable and the art of compliment
}

\begin{abstract}
This research aims to shed light on the concept of ethics from a Western, philosophical and Islamic perspective, and the extent of disparity in opinions in defining the concept of moral values and their source. And their mental judgments that come from them, but from the Islamic point of view, moral ideals are seen as the relationship of the individual to his Lord and society, and this study also came to talk about the most important poetic purposes, which is praise and its concept and its relationship to the life of the poet and his tribe.

This study included an introduction and a chapter of two sections and a conclusion followed by sources and references, and among the most important findings that the researcher reached is that moral ideals were the subject of controversy and disagreement between Arab critics, ancient and modern, and praise poetry that was said for the purpose of earning. Mamdouh's admiration.
\end{abstract}

Keywords: Eithics, Poem, Abutmmam, Arabs, Literature, Praise

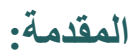

العلاقة بين المديح و إيراز المثل الأخلاقية عند الممدوحين وثثقة؛ فالمديح قائم على أساس إظهار المحاسن

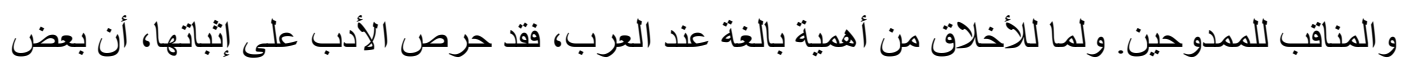
الشعر اء سعوا جاهدين إلى ترسيخ الأخلاق الحميدة في مديحهم، كما يعد المديح لديهم منظومة من الآداب

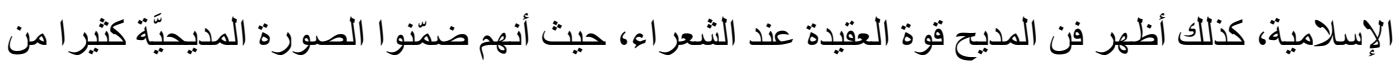
أبيات الحكمة والأدلة النقلية والمنطقية كما هو الثأن في قصيدة فتح عمورية التي مدح بها المعتصم و غير ها من القصائد. 


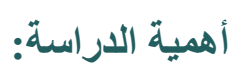

العلاقة بين الثعر والأخلاق علاقة وطيدة؛ فالأدب تعبير عن المجتمع الذي لا يستقيم و لا ينهض إلا بهذه الأخلاق؛ ولهذا ارتبط فن المديح برصد الأخلاق الحميدة للمدوح. من ثمّ يحاول البحث أن يكون إضاءة حول القيم و المثل الأخلاقية، هذه القيم التي تعد مُثنا أخلاقية ترسخت في أذهانتا وسلوكنا، ونقلت هذه المثل الأخلاقية في شعر المديح من مجرد معنًى مدحيّ إلى قيمة عظيمة يدعو إليها الثناعر ، ويستقبلها الفرد المجتمع، و هذا ما دعا الباحثة إلى اختيار هذا الموضوع.

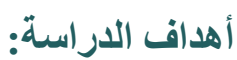

أن الأعر اف و العادات و التقاليد المجتمعيّة تُمتِّل الركيزة الأساسية التي يستمد منها الفرد أولويات سلوكه، و هذا يُفسر التباين في المثل الأخلاقية بين المجتمعات، فلكل مجتمع أو أمة مُنلاها المختلفة عن غيرها من بن الأمم، و إن كان بينهم مُتُل مشتركة، فالكرم يُعد من أهم المكارم عند العرب، و لا نجده بهذه الأهمية عند الغربيين، و النظرة للرجولة في المجتمع العربي ليست كمثيلتها في المجتمعات الغربية من حيث: الطبيعة و المهام و المسؤوليات... و هذا لا ينفي اشتر اك البشر بقيم ثابتة لا تتغير و إن تباينت درجة اهتمام المجتمعات بها، كالصدق و الأمانة و الثجاعة... إلخ. ولان.

وقد اختلفت الأخلاق عند العرب قبل الإسلام عما أصبحت عليه بعد الإسلام؛ فقد اتصف العرب ببعض

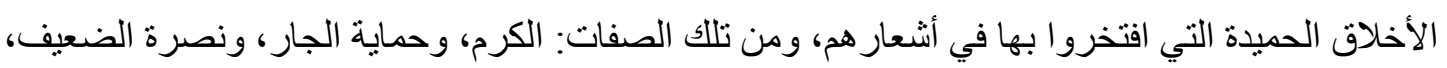
وحفظ الأعر اض. وكان للعرب-قبل الإسلام- عادات سيئة بعيدة عن مكارم الأخلاق، مثل: العبودية، و التعدي على غير هم، وو أد البنات، و التشاؤم، و التعصب القبلي، فلما بزغت شمس الإسلام، دعاهم إلى التخلي عن بعن هذه الأخلاقيات السيئة مؤكداً أنه دين الأخلاق الحميدة.

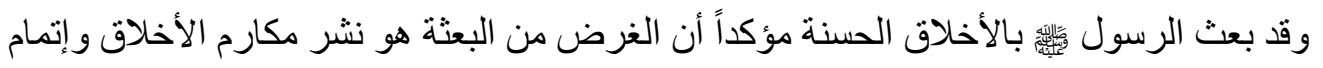
نو اقصها، فقال : في الخلق زاد عليك في الدين"(2).

(1) محمد بن إسماعيل البخاري (ت256هـ)، الأدب المفرد، حققه وقابله على أصوله سمبر بن أمين الزهيري، مكتبة

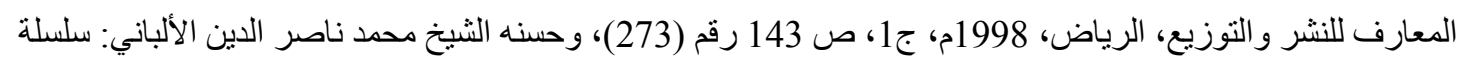
الأحاديث الصحيحة، مكتبة المعارف للنشر و التوزيع، الرياض، ط1، 2004م، ج 1 ص الن 112، رقم (45).

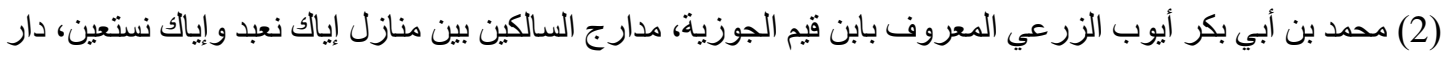

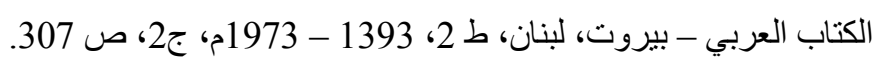


ويُرغِّب رسول اله في الأخلاق الحسنة مؤكدا أن خير الناس أحسنهم خُلقا فيقول: 》اإنَّ مِن خياركم أحسنَكم

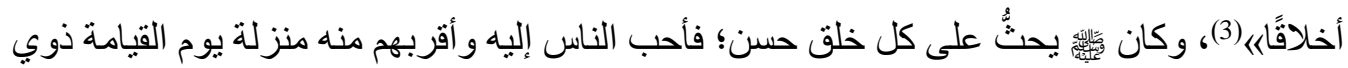
الأخلاق الحميدة، وفي ذلك يقول: اإن من أحبّكم إليَّ و أقربكم مني مجلسًا يوم القيامة أحاسنَكم أخلاقًا ...

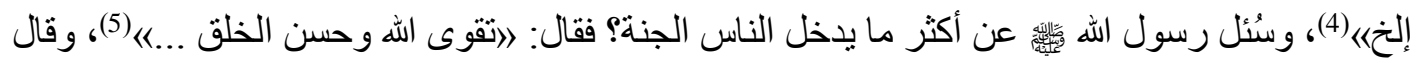

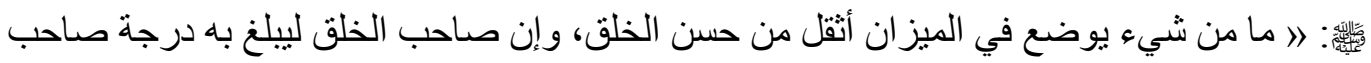

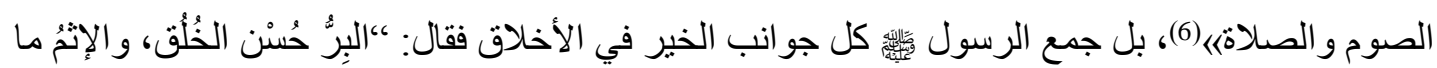
حاك في صدرك، وكر هتَ أن يطَّع عليه الناس"(7). هذا غيض من فيض؛ فالثو اهد الدالة على منزلة الأخلاق في الدين الإسلامي الحنيف كثيرة؛ فالأخلاق سبب في سعادة المسلم في الدنيا و الآخرة لكونها توجه سلوكه إلى فعل الخيرات، وترك المنكر ات، قد كانت أخلاق التجار الإسلامية سببا رئيساً في دخول كثثبر من الناس الإسلام من كل حدب وصوب، ودئ ولا يز ال الإسلام ينتشر في بلاد العالم بقوة الأخلاق وتعاليمه السمحة.

ومن أجل ذلك ازدادت عناية الأمة الإسلامية بالأخلاق، وخاصة بين مثقفيها و علمائها وشعر ائها، وكثر إنتاجهم الثقافي و الثعري في دعم الأخلاق الحميدة. و هذا يأخذنا حثيثا إلى موضوع الدراسة؛ فقد زادت عناية الثعر بالأخلاق و المثل الأخلاقي، وتتاول الثعر اء الأخلاق في أغر اض الثعر كافة: الغزل، و المديح، والفخر، والرثاء، حتى الهجاء كان بذكر مثالب القوم و أخلاقهم القبيحة.

ولعل ذلك ما دفع الباحثة إلى الخوض في غمار هذا الموضوع بحثا ودر اسة؛ فهذه الدراسة لإظهار أثر المثل الخلقي في الثعر العربي.

(3) محمد بن إسماعيل بن إبر اهيم بن المغيرة الجعفي البخاري (ت256هـ)، الجامع المسند الصحيح المختصر من أمور

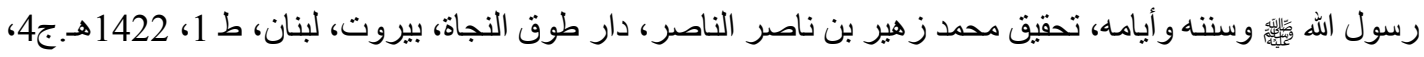

$$
\text { ص189 صرقم (3559). }
$$

(4) محمد بن عيسى أبو عيسى الترمذي السلمي، سنن الترمذي، تحقيق: أحمد محمد شاكر و آخرين، دار إحياء التراث

$$
\text { (5) العربي - بيروت، حديث رقم (2018) المرجع السابق، حديث رقم } 2004 .
$$

(7) مسلم بن الحجاج القنيري النبسابوري، صحيح مسلم، تحقيق محمد فؤاد عبد الباقي، دار إحياء الكتب العربية لعيسى البابي الحلبي، توزيع دار الكتب العلمية، بيروت، لبنان، ط1، 1991م، حديث رقم (2553). 
الهجلة الدولية لنشر البحوث والدراسات

International Journal of Research and Studies Publishing
المجلد الثالث - الإصدار الثالث والعشرون تأريخ الإصدار: 20 سبتمبر 2021م

منهج الاراسة:

و أما عن المنهج العلمي المتبع في هذه الدراسة هو المنهج الوصفي التحليلي الإحصائي يقوم على تسلسل منطقي للأفكار.

محتوى الدراسة:

وقد اشتملت هذه الدر اسة على مقدمة، وفصل و احد من مبحثين، وخاتمة تتضمن أهم النتائج و التوصيات التي توصلت إليها الدر اسة. وفيما يلي بيان بالبناء الهيكلي للار اسة وفق الآتي:

المقدمة: يعرض للمقدمة النظرية للار اسة، و المنمثلة في: أهمية الدر اسة، وأهدافها، ومنهج الدراسة، وحدود الدراسة.

الفصل الأول: (المثل الأخلاقي وفن المديح)، وقد اشتنمل على مبحثين: المبحث الأول: (مفهوم المثل الأخلاقي): تتاول تعريفًا شاملًا كاملً للمثل الأخلاقي والأخلاق عند العرب و غير هم، قديمًا وحديثًا، ويستعرض رؤية الباحثين و المفكرين للأخلاق، ودور ها في تتمية المجتمعات،

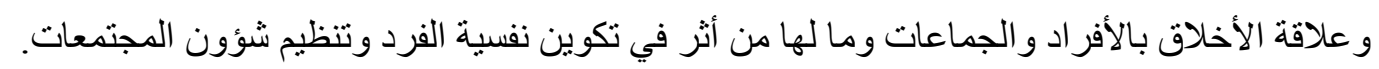
وبرز في هذا المبحث أوجه الاتفاق والاختلاف بين وجهة النظر الإسلامية المتعلقة بموضوع الأخلاق ووجهة النظر اليونانية والنظرة الغربية في ذات الثأن. كما تطرق إلى ما يمكن أن بنطوي تحت منظومة ولنها

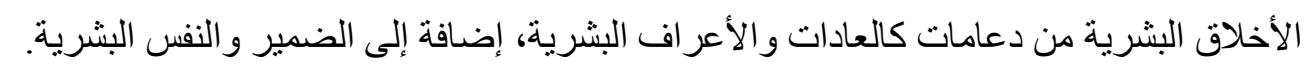

المبحث الثاني، وقد جاء بعنوان: (العلاقة بين فن المديح و المنل الأخلاقي)، و ابتُدئ هذا المبحث بتعريف المدح مع إير اد شواهد قر آنية وشعرية، كما مال إلى تأصيل كلمة المدح ببيان جذر ها اللغوي و الاصطلاحي. وتطرّق المبحث إلى بيان أسلوب المدح وطر ائقه اللغوية.

وكذلك بيان أهمية غرض المدح بين أغر اض الثعر العربي، وما لهذه الأهمية من صلة وثيقة بحياة الثاعر القبلية، و علاقته بقبائل ممدوحيه، وظهر هنا التدرج الذي و اكب تطور الددح في الشعر؛ إذ بدأ مدحًا خالصًا

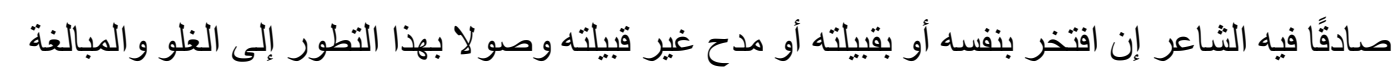
بسبب التكسب بالثعر ـومن وجهة نظر أخرى نجد أن وصول المدح إلى باب التكسب قد أكسب الثعر ألوانًا جديدة و عناية بالغة من الثاعر حول القصيدة قبل أن يظهر ها إلى العلن. 
الهجلة الدولية لنشر البحوث والدراسات

International Journal of Research and Studies Publishing
المجلد الثالث - الإصدار الثالث والعشرون تأريخ الإصدار: 20 سبتمبر 2021م

\section{المبحث الأول: مفهـوم المثل الأخلاقي}

الدعوة إلى المُثل الأخلاقية من أفضل الدعوات التي دعا إليها الدين الإسلامي؛ ولكونه دين الفطرة فإن كل مولود مفطور على حب الخير لله وللناس؛ فالأخلاق تعمل على تغذية الثعور الإنساني، وتكيُّف الفرد تكيفًا

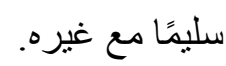

فالأخلاق "صفة مستقرة في النفس- فطرية أو مكتسبةـ ذات آثار في السلوك محمودة أو مذمومة"(8). وقد

عرَّفها الجرجاني بقوله: "عبارة عن هيئة للنفس راسخة تصدر عنها الأفعال بسهولة ويسر من غير حاجة

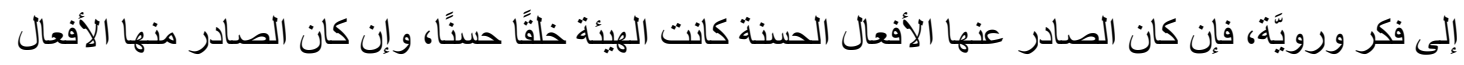
القبيحة سُمَّيت الهيئة التي هي مصدر ذلك خلقًا سينًا" (9).

و الأخلاق منها ما هو ذاتية: كالثجاعة، والأمانة، والثقة بالنفس. ومنها ما هو مجتمعية: كإعانة المحتاج، و الحلم، والعفو عن الناس، الإحسان إليهم، والوفاء بالعهود.

وسوف تسلط الباحثة الضوء في هذا الورقة العلمية على الأخلاق من منظور غربي وفلسفي و إسلامي. فالنظرة الفاحصة على المنظور الغربي للأخلاق تدل على تفاوت أر اء فلاسفة أوربا في تحديد مفهوم القيم، يقول ر الف بارتن: "الحقيقة أنه لا يوجد للقيمة معنَى ثابت ... فمختلف الناس يعنون أثنياء مختلفة في سياقات

مختلفة"(10).

ومن "أجود ما قيل في القيم عند الغربيين هو: إنها محطات أو مقاييس نحكم بها على الأفكار والأشخاص و الأشياء والأعمال من حيث حسنها وقيمتها أو من حيث عدم قيمتها" (11).

وتتسم القيم الثخصية بأنها متغيرة لكونها تتغير من بداية حياة الإنسان؛ فهي تنمو في مرحلة مبكرة من

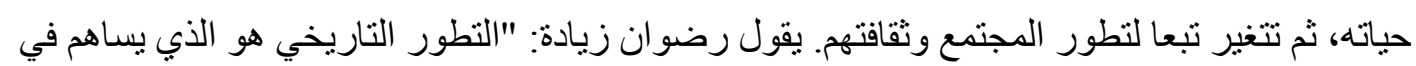
تحديد القيم الشخصية"(12).

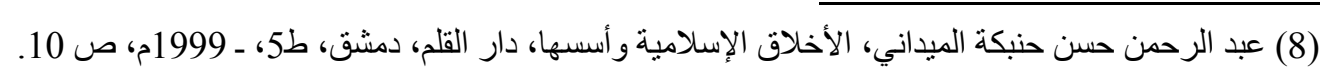

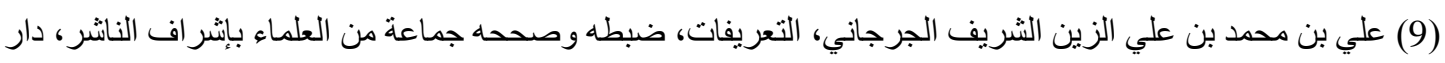

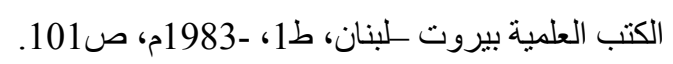

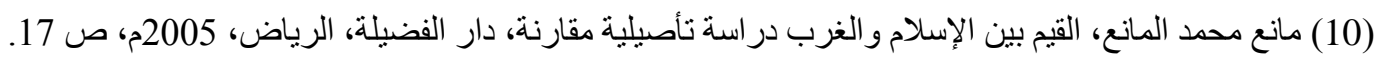

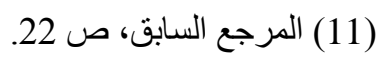

(12) رضوان زيادة وكيفن جيه، صر اع القيم بين الإسلام و الغرب، دار الفكر، دمشق 22 2010م، ص 47. 
أما من حيث مصدر القيم والقول بأنها نشأت من صنع المجتمع أو الفرد نفسه، فيرى أندريه بريدو: أن "القيم مصدر ها الأحكام الثخصية أولًا، أحكام القيمة التي يصدر ها الثخص على الأشياء بناءً على حاجته إليها أو منفعته، وشينًا فثنيًًا تتموضع القيم مع الحياة الاجتماعية لتصبح ذات طابع اجتماعي"(13).

إذن نظرة الغرب للأخلاق هي نظرة متغيرة نسبية، قو امها مصلحة الجميع. واعتمدت على الإنسانية و الديمقر اطية التي تعد عند الغرب من أهم القيم التي تتيح للأفر اد و الجماعات التعايش و التو افق معًا.

و هكذا اختلفت الأخلاق من أمة إلى أخرى؛ فالأخلاق عند فلاسفة اليونان تختلف في توجهها عن الأخلاق عند غير هم من الأمم والثعوب الاخرى، والنظرية الأخلاقية في الإسلام تختلف عن الفلسفة الأخلاقية في مذاهب الر أسمالية أو النفعية و الاشتر اكية.

فالأخلاق عند فلاسفة اليونان (سقر اط و أفلاطون و أرسطو) تختلف في منهجها عن منهج السفسطئيين الأخلاقي؛ فهي عند الفلاسفة تتميز بأنها مطلقة ثابتة، بيد أن السفسطائيين برون أنها نسبية متغيرة؛ وذلك لاختلافهم حول "الهدف الذي رآه السفسطائيون بأنه مصلحة شخصية. في حين كان أفلاطون ممن عارضو الهي

هذا الفكر ، ور أي أن ذلك بهدم الفضيلة، ويشوه الهدف الحقيقي من الأخلاق"(14). ووقف سقر اط في وجه السفسطائيين ر افضًا نظريتهم الأخلاقية؛ مؤكداً أن الأخلاق مطلقة "لا تختلف باختلاف الزمان و المكان، و لا

$$
\text { تتغير بتغير الظروف والأحوال"(15). }
$$

و الحقيقة أن الأخلاق في الفلسفة اليونانية قامت على تمييز الثعب اليوناني وتفضيلهم على غيرهم، وقد نأثر بذلك الإنسان الأوربي؛ فدفعه ذلك إلى تحقير ما دونه من أجناس أخرى، وتبرير استعمار الثعوب غير الأوروبيين و استغلالهم و استعبادهم، يؤكد ذلك الفيلسوف البريطاني برنر اند رسل قائلا: "لقد أخطأ اليونان خطأ فاحشًا حين أحسو اشعور السيادة على الشعوب البربرية، و لا شك أن أرسطو قد عبَّر عن فكرتهم العامة في ذلك حين قال: إن أجناس الثمال مليئة بشعلة الحياة وأجناس الجنوب متحضرة، و اليونان وحدهم هم الذين يجمعون الطرفين: فنعلة الحياة تملؤهم، و هم- في الوقت نفسهـ متحضرون. و أفلاطون و أرسطو كلاهما قد

ذهبا إلى أنه من الخطأ أن يُنَّخذ من اليونان عبيد، لكن ذلك عندهما جائز بالنسبة للشعوب البربرية"(16).

وتتفق الفلسفة النفعية مع ر أي السوفسطائيين في أن الأخلاق نسبية، وكل ما يحقق منفعة الفرد فهو خير؛ فمذهب النفعية يقوم على "أساس أن اللذة هي الغرض الوحيد الذي تهذف إليه رغبات الإنسان، 
و أنها مستوى الأفعال الإنسانية ومعيار الأحكام الخُلقية، وكلا الأمرين لا يصمد للنقة؛ ومن هنا كان تداعي

$$
\text { النفعية بتداعي الأسس التي قامت عليها"(17). }
$$

و أما فلسفة العقليين، و إمامهم الفيلسوف الألماني إيمانويل كانت، فلم تعترف باللذة مقياساً للأخلاق، بل عدّوا "الواجب أمر ا مطلقا يتنافى مع نزعاتنا الطبيعية وميولنا الفطرية، و أقامو ا الأخلاقية على قهر النفس ووأد مطالبها وقمع رغباتها (18).

ونجد أن الفلسفة الوضعية تتناغم إلى حدٍّ كبير مع المنطق الحقيقي لجو هر المُنّل الخلقية و علاقتها بالفرد و المجتمع؛ فتشير إلى أن المثل الأخلاقية علم واقعي يخضع لأسلوب الاستقر اء، وينصب نركيزه على الملاحظة، ويتجلى في العادات و الأعر اف و المثل العليا للجماعة، وللفلسفة الأخلاقية ملامح كثيرة، منها: - إنها تعتمد على الملاحظة، وتنظر للثخص نظرة واقعية. - إن المثل الأخلاقية نسبية وليست ثابتة؛ لاعتبار هم أن المعرفة نسبية. - إن الميول نحو الآخر أمر فطري، وهي أساس الأخلاق في تعامل الثخص مع غيره. - إن مصدر المثل هي الميول و العو اطف الفردية بين البشر، ثم تتطور لتصبح عواطف ذات صيغة عقلية

ويرى “،أفلاطون أن المُتل هي الخير، ومصدر الوجود و الكمال. أما جون ديوي فيعتبر الأفكار والمَتَل الأخلاقي مجرد وسيلة وذريعة يستعين بها الفرد لتوجيه سلوكه للوصول إلى مطالبه و غاياته"(20). و هذ يعني أن ديوي ينظر إلى الأخلاق على أنها وسيلة تحقيق غاية عظيمة؛ فإن كانت المُثل ليست إلا جسرًا يَعبُر من خلالها الفرد إلى أهدافه و غاياته؛ فإن ذلك يتنافى مع النظرية اليونانية المعتمدة على العقل؛ فالفرد ليس بحاجة للمثل الخلقية للوصول إلى هدفه إلا إن كان الأمر من باب الخداع، وهذا أمر فردي ليس عامَّا.

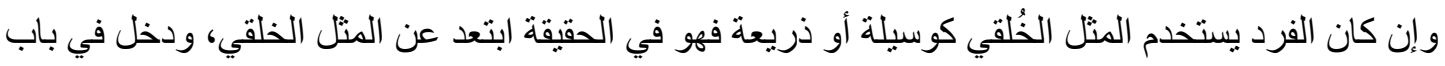
النفاق الاجتماعي أو الوظيفي، أو أي نوع من النفاق الذي هدفه تحقيق المصلحة للذات. أما ابن مسكويه فقد عرَّف الأخلاق قائلًا: "إنها حال للنفس داعبة لها إلى أفعالها من غبر فكر و لا روية"، ثم قام بتقسم الأخلاق إلى قسمين، هما: (17) نوفيق الطويل، مذهب النفعية العامة في فلسفة الأخلاق، مكتبة النهضة المصرية، القاهرة، ط1، 1953م، ص295.

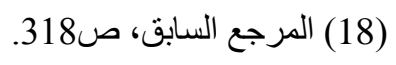

(19) مصطفي حلمي، الأخلاق بين الفلاسفة وعلماء الإسلام، دار الكتب العلية، بيروت، 2004 م، ص 74.

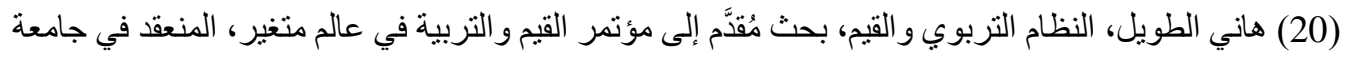


الهجلة الدولية لنشر البحوث والدراسات

International Journal of Research and Studies Publishing
المجلد الثالث - الإصدار الثالث والعشرون تأريخ الإصدار: 20 سبتمبر 2021م

$$
\text { أولَاً: ما يكون طبيعيَّا من أصل الإنسان، والذي يحركه أدنى شيء في الإنسان. }
$$

وثثانيًّا: ما كان مستفادًا بالعادة و التدريب، وربما كان مبدؤه بالروية و الفكر ثم يستمر عليه حتى يصير ملكة

خلقًا" (21).

ويثير الساعاتي إلى أن: "المثل: مفاهيم عاطفية تقوم على أسس نفسية اجتماعية يوجدها الإرث الاجتماعي

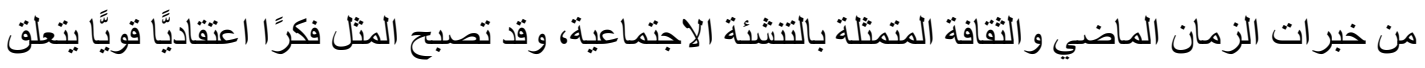

بأثنياء مفيدة داخل الحياة الاجتماعبة"(22).

وفي الحقيقة أن هذا التعريف قد أجْمَل كل ما يتعلَّق بالمُثل من خبرات حياتية وثقافات ومعتقدات اجتماعية، بينما يرى غريب أن المنل: "نسبية، وتختلف من شخص لآخر بناءً على الحاجات و الرغبات و الظروف المحيطة بالفرد؛ بمعنى أنها إنسانية شخصية" (23).

و هذا كلام سليم؛ لأن المجتمع بأعر افه وتقاليده وقو انينه ليس قادرًا على توحيد كل الناس على منظور أخلاقي و احد؛ ففي البيت الو احد تجد تباينًا في تبنّي الأفكار، ومنها المُتل الأخلاقية؛ و عليه وجدنا الباحث يصفها بأنها نسبية، وتختلف من شخص إلى آخر. وتُعرِّف المثل بأنها: "مجموعة من الأحكام التي يصدر ها الفرد على المحبط الإنساني والاجتماعي؛ فهي نتاج اجنماعي تقبَّله الفرد ورضي به "(24).

ويُعرِفُهُها عوض بأنها: "مجمو عة المعايير الاجتماعية الانفعالية التي تتصل بمستويات خلقية تُقدُِّها الجماعة، ويتشربها الفرد من خلال التفاعل مع الآخرين"(25).

ويرى بركات أنها: "مجمو عة من المعايير التي تتبثق من مجتمع ما، وهي بمنزلة القدوة لهم، و عليهم الالنزام بها، وأن الخروج عنها بمنزلة الخروج على المجتمع ومثله العليا"(26).

(21) ابن مسكويه، تهذيب الأخلاق وتطهير الأعراق، تحقيق: ابن الخطيب، مكتبة الثقافة الدينية، القاهرة، د.ت، ص 41.

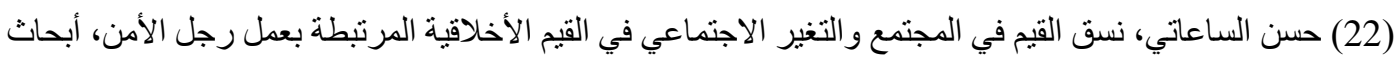

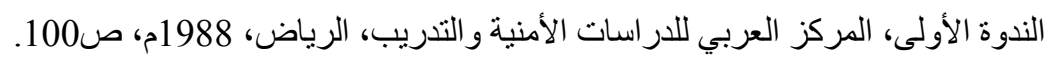

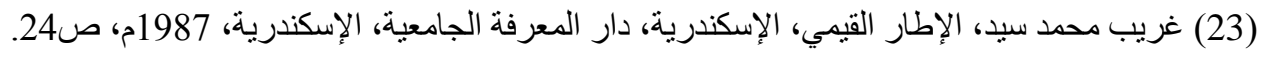

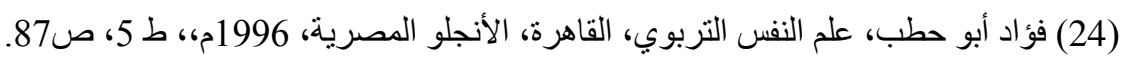

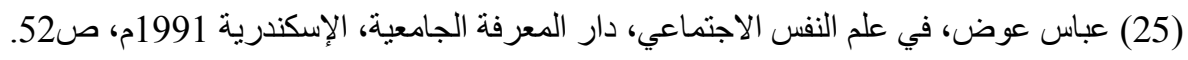

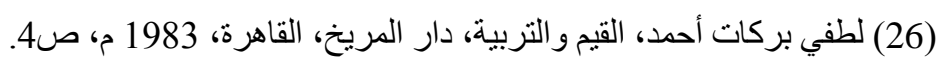


كما يُنْظر إلى المثل على أنها: "وحدات معيارية اجتماعية يلتزم بها أفر اد جماعة ما، وتميز السلوك المر غوب فيه من السلوك غير المرغوب فيه. وهي إصدار الحكم القيمي للمشكلات الاجتماعية والخيار ات الخلقية"(27)

ونُُْرَفَ بأنها: "القيم الحقيقية التي يُحْكَمِ من خلالها على السلوك الخلقي وتحكمه، و هي تُخْضِعُ الفعل و السلوك و الهدف من العمل على مستوَى مقبول أو غير مقبول". (28) ويمكن القول: إن المُثُل الأخلاقية تثثير إلى:

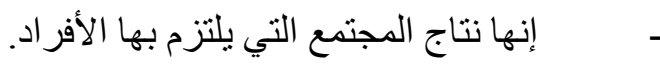

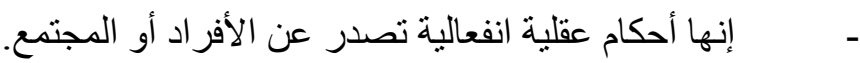

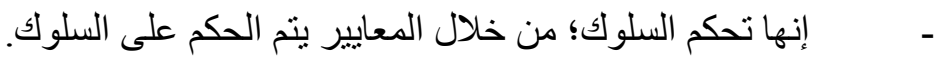

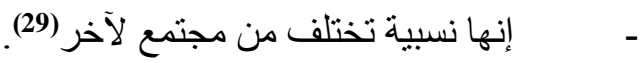
وقد جعل الإسلام الأخلاق وسطا بين الفلسفتين: فلسفة النفعيين وفلسفة العقليين؛ فلم يُبح اللذة للإنسان مطلقا، ولم يقهر النفس البشرية ويقمع رغباتها، فلا رهبانية وتشددا، و لا تهاونا وتفريطا. ويؤكد ذلك قوله تعالى:

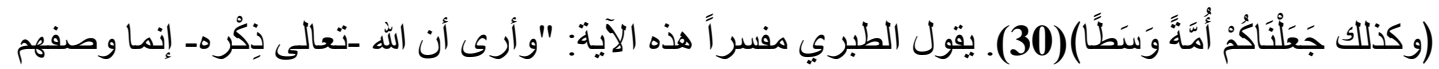

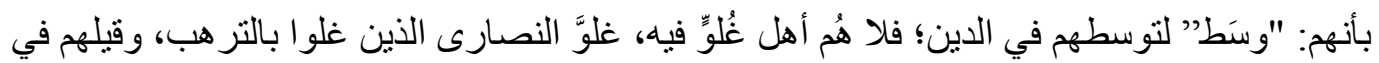

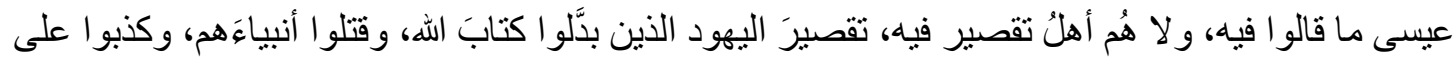
ربهم، وكفرو ا به، ولكنهم أهل توسط واعتدال فيه؛ فوصفهم الله بذلك، إذ كان أحبَّ الأمور إلى الله أوْنطُها" (31)

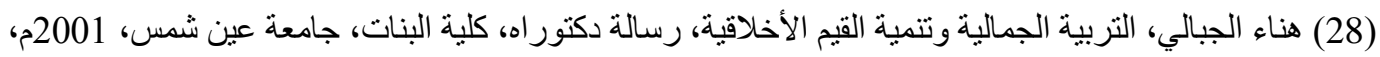


ومن الناحية الإسلامية يُنظر إلى المُنّل الأخلاقية بأنها: "علاقة الفرد بربه و المجتمع، ونظرة الفرد لنفسه

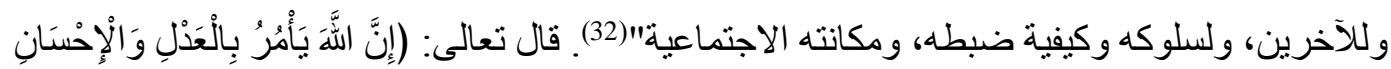

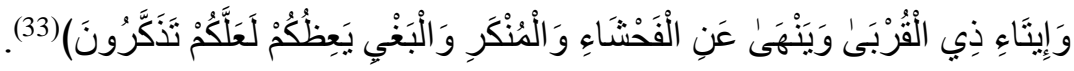
ويُعرِّفها كفافي بأنها: "المعتقدات و الأحكام المستمدة من القرآن الكريم و السنة النبويـة، والتي يمثّلها الإنسان المسلم ويلتزم بها، و التي يتحدد في ضوئها علاقته بـالله ـتعـالى-، و اتجاهاته نحو الحياة الآخرة، وموقفه من بيئته المادية و الإنسانية"(34).

وقد عَرَّف جابر قميحة المثل الأخلاقية بأنها: "مجموعة من الأخلاق التي تصنع شخصية الفرد، وتجعل منها شخصية متكاملة قادرة على التفاعل مع الآخرين، والتو افق مع أعضائه، و أشارت إلى المثل الإيجابية التي يجب التحلي بها، كمكارم الأخلاق، و الصدق و الرحمة و الكرم و غير ها من هذه المثل"(35). ويثير إبر اهيم

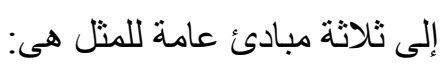

$$
\text { - }
$$

ومن خلال ما تقدَّم عند هذين الباحثين (كفافي، جابر قميحة) نلحظ أن نظرتهما للمثل الخُلقي نابعة من منظور إسلامي بالدرجة الأولى، ومن العادات والتقاليد العربية؛ فاهتمامهما بالجانب الروحي و اضح، على خلاف ما وجدنا عند المفكرين الغربيين.

"فالمُتنل الأخلاقية تأخذ أبعادًا روحية ووجدانية واجتماعية، فمن الناحية الاجتماعية تؤدي دورًا ساميًا في قوة

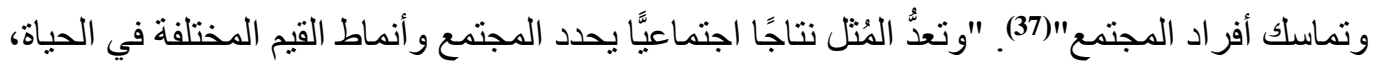

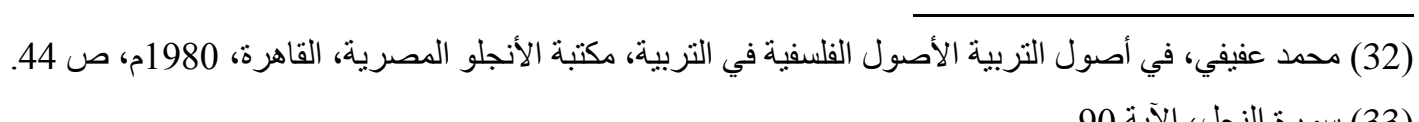
(33) سورة النحل، الآية 90. (34) محمد كفافي، تصنيف مقتر ح لبعض القيم الإسلامية، مجلة الأبحاث التربوية، السنة السابعة، العدد 14، مصر، 
الهجلة الدولية لنشر البحوث والدراسات

International Journal of Research and Studies Publishing
المجلد الثالث - الإصدار الثالث والعشرون

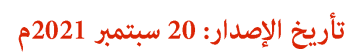

ISSN: 2709-7064

و هي مُلزِمَة للفرد و الآخرين"(38). "ومن الناحية الروحانية فهي التي تتحكم بالسلوك بناء على اهتماماته

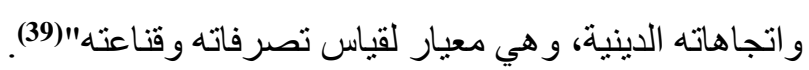

و هذا ما يؤكد أن الباحثينِ قد ارتكزَا على ذلك في تعريفهما للمُتل الأخلاقية؛ فالمفكر المُسلم لا يرى انفكاكًا للمثل عن الدين الإسلامي؛ إذ إن إلزام الفرد بالكُتل من أهم ما جاء به الإسلام، قال ـتعالىــ واصفًا سيدنا

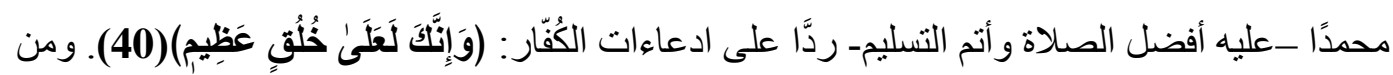
خلال حديث لرسول لله

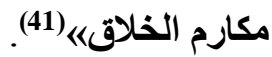

وخلاصة القول: إن الدين الإسلامي قد رسَّخ القيم و المثل الإنسانية النبيلة في نفس المسلم و عقله، وهذا الأمر قد انعكس على المجتمع المسلم، فحياة المسلم تسبر وفق المنهج الإسلامي الرباني؛ لأن القيم و المُنتل في

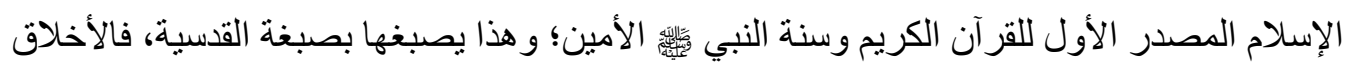
الإسلامية ثابتة ومرنة وشاملة لكل مر احل العمر ، صالحة لكل زمان وكل مكان، وهذا ما لم تتادى به الفلسفة اليونانية، ولم تقل به معظم الفلسفة الغربية خاصة القائمة على النفعية.

المبحث الثاني: العلاقة بين فن المديح والمثل الأخلاقي

بعد التعرف على مفهوم المثل الأخلاقي، يجدر بنا أن نتعرف على المديح لغة و اصطلاحا. فمعنى المديح في

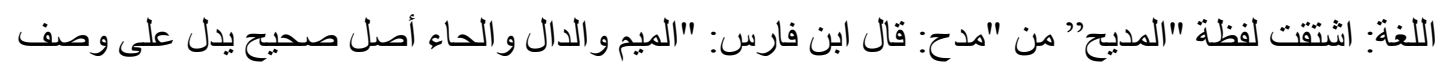

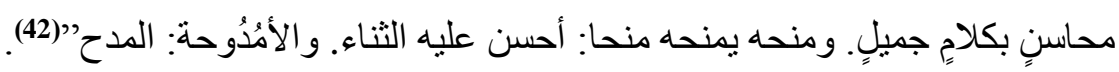

فالمديع: "هو إحسان الثناء على المرء بما له من الصفات الحسنة، مَحَحَهُ كمنعهُ، مَدحًا ومدحةً: أحسن الثناء عليه .... و المديح و الأمدوحة ما يمدح به، جمعه: مدائح، و أماديح"(43).

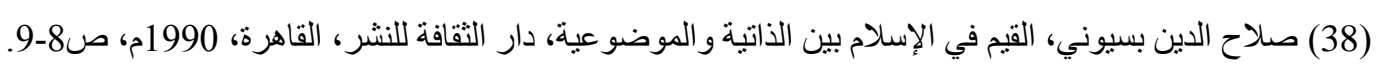

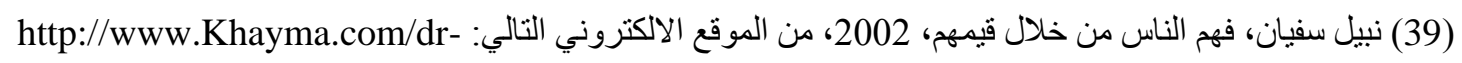

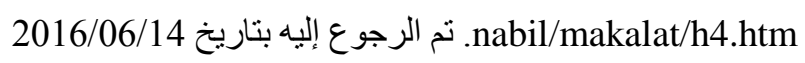
(40) سورة القلم، الآية 4.

(41) الإمام ماللك بن أنس، الموطأ، تحقيق: محمد فؤاد عبد الباقي، دار إحياء التراث العربي، 1985، ص 904.

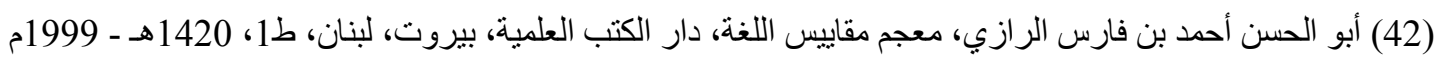
ص 503 (مادة: مدح).

(43) مجد الدين محمد بن يعقوب الفيروز آبادي، القاموس المحيط، تحقيق: مكتب تحقيق التراث في مؤسسة الرسالة،

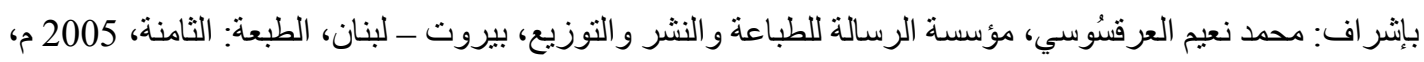


و لا يقتصر المديح على الثعر بوجه خاص أو الكلام بوجه عام، بل إن” المديح: خطبة أو حديث أو كتابة تطري إنسانا أو إنجاز ا، وتهيل عليه الثناء بغير حساب"(44). وشاع المديح عند العرب في أقو الهم وكتاباتهم، وانتشر وازدهر في الثعر والنثر على حد سواء، وللعرب فيه

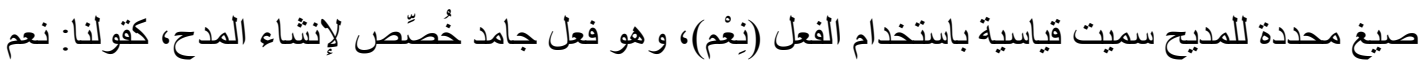

الرجل العابد، ونعم الفتاة المحتشمة، واستخدم هذا الفعل في القرآن الكريم بعدة مو اضع، منها قوله تعالى:

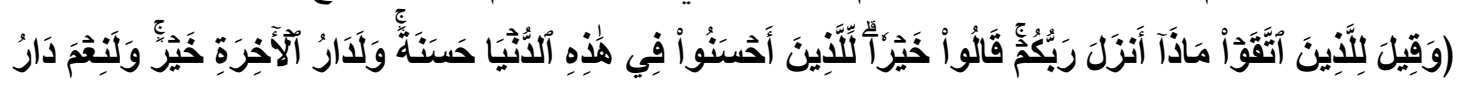

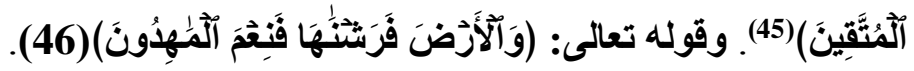
وفي الثُعر قال زهير يمدح سنان بن أبي حارثة المُرِّي (47): حَضَرُوا، لَََى الحُجُراتِ، نَارَ المَوْقٍِِ نِعْمَ الفَتَىى المُرِّيُ أَنْتَّ، إِذا هُمُ أو باستخدام الفعل حَبَّذا، وهو أيضًا فعلّ جامد، صيخ لإنشاء المدح، وجاء مركبًا مع اسم الإشارة (ذا) كقولنا: حَبَّذا الرجلُ المخلص، حَبَّنا المر أُةٌ المُخلصة، أما في الثُعر فمنه قول جرير (48): وَحَبََّْا سَكَاكِنُ الرَيَّانِ مَنْ كِانَا

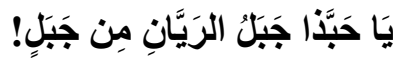

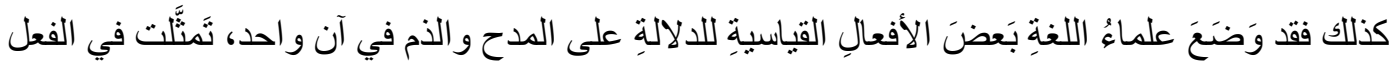

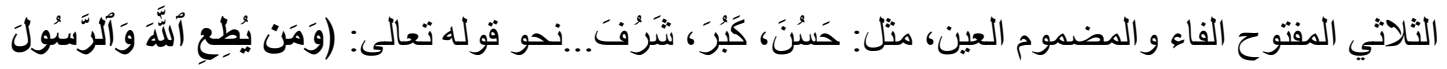

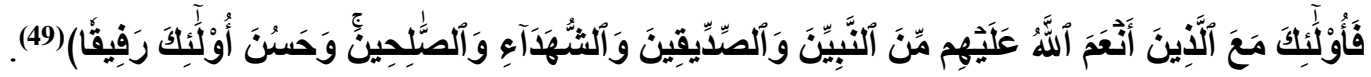
أسَّا الصيخ الأخرى للمدح التي تسمى غير قياسية أو سماعية فهو الذي دل على معنى المدح دون استخدام هذين الفعلين: (نعم، حَبَّذا)، وله ألفاظ كثيرة متعددة تقود إلى معنى المدح دون صِيغِ محددةٍ سو اء في النثر أو الشعر ، مثل: لله دره... و غير ها. ومن ذللك: قول المتنبي في وداع أبي العشائر (50): وَالْبَأَسُ بَاعُ وَأَنْتَ يُمْنَاهُ

والْجُودُ عَيْنْ وأَنْتَتَ نَاظِرُهَا

(44) إبر اهيم فتحي، معجم المصطلحات الأدبية، نشر المؤسسة العربية للناشرين المتحدين، طبع التعاضدية العمالية

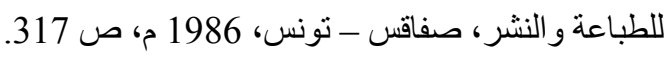
(45) سورة النحل؛ الآية 30.

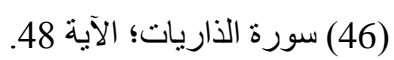
(47) زهير بن أبي سلمى، ديو ان زهير بن أبي سلمى، تحقيق: علي حسن فاعور ، دار الكتب العلمية، بيروت، ط1، 1986م، ص47) مبر البحر الكامل. (48) جرير بن عطية الخطفي، ديوان جرير ، ديو ان العرب، دار بيروت، بيروت 1986م، ص493. صوبـ البحر البسيط. (49) سورة النساء؛ الآية 69 (40) (50) أحمد بن حسين الجعفي المتنبي أبو الطيب، ديوان المتنبي، دار بيروت، بيروت 1983م، ص252. البحر الو افر 
ويُعدُّ بيت جرير السابق أمدح بيتٍ قالته العرب، فقد وصف ممدوحة بالثجاعة في الثطر الأول، وبالكرم في الثطر الثاني، في حين يظهر الكرم في الثطر الأول عند المتنبي وتظهر القوة والثجاعة في الثطر الثاني.

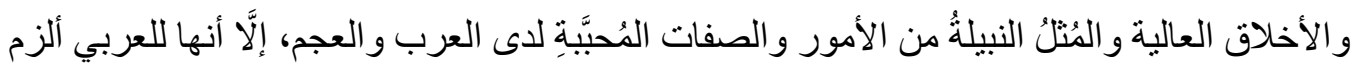

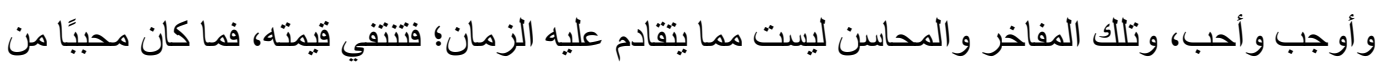
الصفات الكريمة في الجاهلية بقي محبًِا في الإسلام، ولم بنتقص من قيمته، بل إن الإسلام أقرَّ بعض العادات

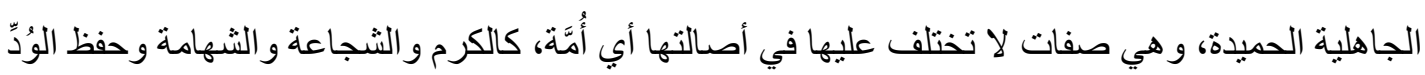
و العهر و الحكمة و التَّأني.

وقد تَنَوَّعت أغر اض الشعر العربي بتنوع المُناسباتِ والوقائع التي يعيشها العربي؛ فكانت قصائد الفخر

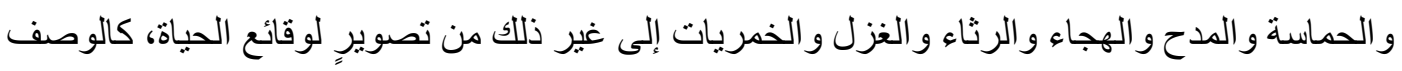
إضافة إلى النصائح و المو اعظ.

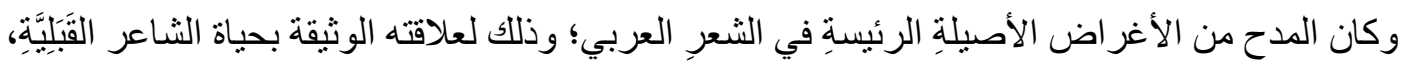

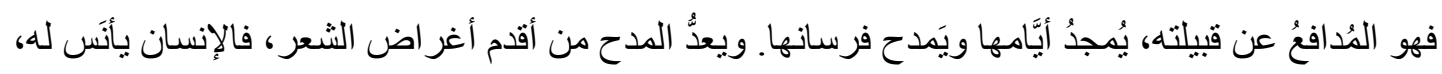
ويضفي على النفس شبيًا كبيرًا من الألفة و الر احة؛ وذللك لما له من أثر بالغ في العاطفة، وهذا يجعلنا نربط بدايات المدح بالغزل، فالغزل أساسه الثناء على الحبيب وتصوير العو اطف و الأشو اق، ثم يتناسب الأمر أيضا مع الفخر فما هو إلاّ مدح للذات وللقبيلة. ومن الأدلة على ذلك ما قاله عمرو بن كلثوم في معلقته(52):

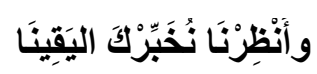

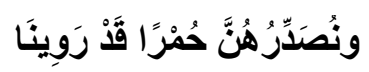

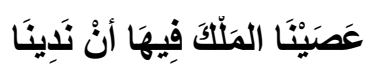

بِتَاجِ المُلْلَكِ يَحْمِي المُحْجَرِينَا
أَبَا هِنْ فَلَا تَعْجَلْ عَََيْنَا

بأنَّا نُورِدُ الرََّايَاتِ بِيضًا

وَأَيََّامٍ لَنَا غَرِّ طِوَالِ

وسنَِِِّ مَعْشَرِ قَدَ تَوَّجُوهُ

(51) جرير بن عطية الخطفي، ديوان جرير، ص77. البحر الو افر.

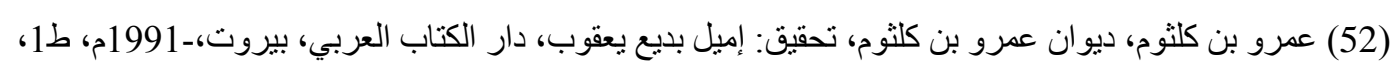

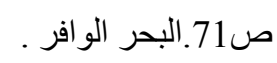


الهجلة الدولية لنشر البحوث والدراسات

International Journal of Research and Studies Publishing
المجلد الثالث - الإصدار الثالث والعشرون تأريخ الإصدار: 20 سبتمبر 2021م

ففي الحقيقة هذه هي مفاخر بالقبيلة ومن ثم هي مدحٌ لقبيلته، وبالتالي لنفسه وكان الفخر بالقبيلة من أحد أبنائها

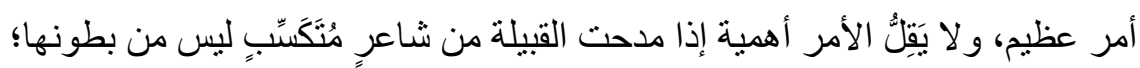

فللمدح أثنرٌ عظيم عند الأشخاص أو القبائل، فالثِعر يرفع شأن الوضيع، ويحط شأنَ الرفيع، ويرفع قبيلةً ويحُطُ أخرى. و ها هو الحُطيئة يمدح قبيلة (أنف الناقة) الذين كانو ا يخجلون من اسم قبيلتهم فيقول (53).

وَمَنْ يُسَوِّي بَأنْفِ النَاقََّةِ الََنَبَا

شَدَّوا العِنَاجَ وَشَدَدوا فَوقَّه الَْكَرَبا
قَوْمُ هُمُ الأَنْفُ والأَنَنَبُ غَيرُهُمُ

قَوْْمُ إذاذ عَقَدُوا عَقْدَا لِجَارِهِمُ

وكذلك الحال عند الحارث بن حِلَّزة يمدح كرم قبيلته (54):

\section{إنْ لمُ يَكنْن لَبَنْ فَعَطَفُ المُدْدَجَج}

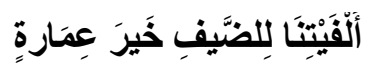

فالثاعر يعمد للمديح ويقصدهُ لأسباب عديدة، منها: إعجاب الثاعر بالممدوح وصفاته ومآثره وفضائله، أو شكره على معروف أسداه إليه أو إلى قبيلته، أو التكسُّب عن طريق المدح. ومثال ذلك في الجاهلية الثناعر النابغة الذبياني الذي تنقل بين الغسانيين وملوك الحيرة مُتكسبًا طامعًا بالصِّلات من النعمان بن المنذر. ومن شعر اء التكسب بالمديح ـأيضًاـ الأعثى الذي جال البلاد متكسبًا مادحًا؛ فقد مدح الأسود بن المنذر اللخمي، فقال (55): (25)

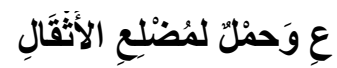

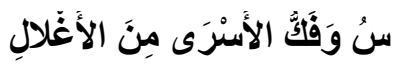

ت حِبَالَّ وَصَتلْتَهَا بِحِبَالِ

ـــ جَزيلًا فِإِتَّهُ لا يُبَالِي
عِنْدَهُ الْحَزْمُ والأتَّقَى وأَسـا الصَّر

وصِلاتُ الأُرْحَامِ قَد عَلْمَ النّا

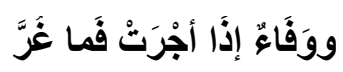

إنْ يُعَاقِبْ يَكْن غَرَامًا وإنْ يُعْـــ

فهو بمدحه هذا - و إن كان مُتكسبًا ـ فإن مدحه يَزْخَر بالمُنَل الأخلاقية و القيم العليا التي يطمح إليها كل ممدوح.

(53) جرول الحطيئة العبسي أبو مليكة، ديوان الحطيئة، برواية وشرح ابن النّكيت، دراسة وتبويب: د. مفيد محمد قميحة، دار الكتب العلمية، بيروت، جرولة 1993م، ط1، ص 45. 4ائه البحر البسيط. (54) الحارث بن ظليم بن حلزة اليشكري، ديو ان الحارث بن حلزة، تحقيق: إميل بديع يعقوب، دار الكتاب العربي، 1991 الحير

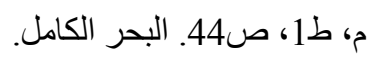
(55) مأمون بن قيس، ديو ان الأعشى الكبير، تحقيق: محمد حسين، الناشر : مكتبة الآداب، القاهرة، ط. المطبعة النموذجية، (د.ت)، ص 9. البحر الخفيف 
ويبدو أن الأمرُ بالمدح بدأ مدحًا خالصًا لصفات أُعجبَ بها الثاعر، أو لإظهار فضائل ممدوحة إلى أن أصبح

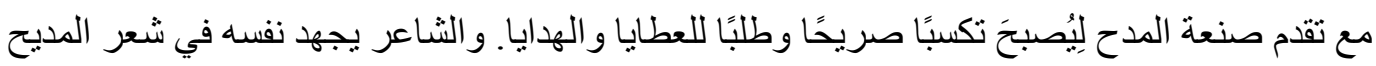
تكسبا أكثر من مدحه بغير تكسب، فنجد أبا تمام “كان يفتت اللغة من أجل الوصول إلى معانيه ويصقلها، ويكثقها، وكان يضع بابتكار اته توقيعه الخاص على عو الم شعرية جديدة اكتسبها بالكدح الثديد"(56). ويمكن القول: إنّ النَكَُّب أكسب الثعر ألو انًا جديدة، و اهتماما بالغًا من الثـاعر في التألُّن بقصيدته، وذلك لتكون محط إعجاب الممدوح؛ ليُجزَل له العطاء، وتمنَّل هذا الاهتمام في التركيز على المُنل الخلقية و التغيير في القو الب الثتعرية التقليدية فجاءت الزخرفة اللفظية وأيضًا الثورة على المقدمة الطللية، كما رأينا عند أبي نو اس ور أينا أبا تمام و المتنبي و غير هم من الثعر اء يمدحون بما لم يكن مألوفًا أو دارجًا فيما قبلهم، وهذا لا لا هُه ينفي وجود تكسب قديم، ولا ينفي وجود زخرف لفظي وبديعي كما أسلفت الباحثة، و هذا لا يقلل من أهمية

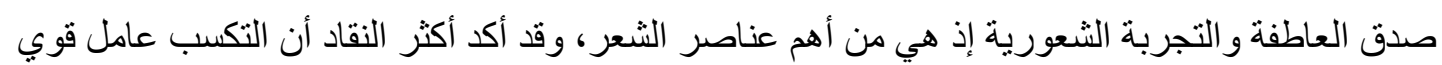
من عوامل الإبداعي الثعري. ويتحدث أبو هلال العسكري عن فضيلة شعر المديح الذي قيل بغرض التكسب فيبين سحره، وقوة تأثيره في الممدوحين، فيقول: "و لا يفوز أحد من موّلفي الكلام كما يفوز به صاحبه من العطايا الجزيلة، و العوارف

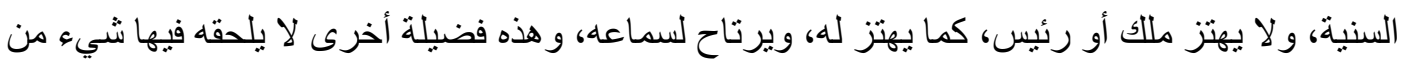
الكلام"(57). فالعسكري ومن تبعه (58) رأوا أن شعر التكسب بلغ "أعلى درجات الإبداع الفني لأن قائله يضطر إلى تجويده وتحسينه؛ ليلائم مقام الممدوحين، ويتصيد به عطاياهم و هباتهم، وينال الحظوة الكبرى لئه

(59)". عند هم

لقد كان أبو تمام يتكسَّب بشعره لكنه كان "شديد الاعتـداد بنفسه، يأبى الذل، ويترَّفع عن الدون"(60). وماذا عن أبي تمام من لوم؟! فإنه "عندما كان يمدح فإنه يساير عصره هـ، ويكتسب قوته" (61).

(56) عبده بدوي، أبو تمام وقضية التجديد في شعره، مكتبة الثباب، القاهرة، د.ت، ص133.

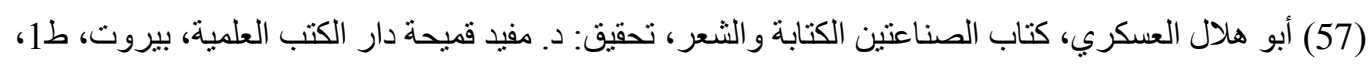

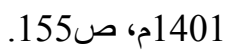
(58) و افقه على هذا الر أي كل من: ابن قتيبة في الثعر و الثعر اء، ص30، ص33. وابن وشنيق في العدة،ج1 ص214.

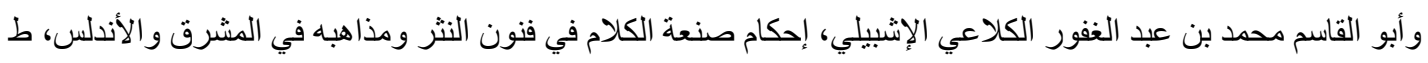

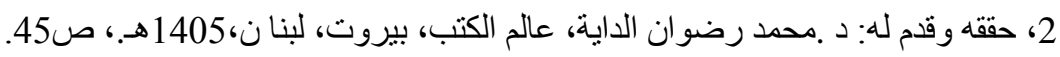
(59) رائد مصطفي عبد الرحمن، ظاهرة التكسب بالثعر وتجلياتها في النقد العربي القديم، مجلة جامعة الأزهر بغزة، دانة،

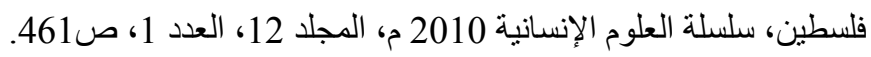
(60) كوركيس عو اد ومخائيل عواد، أبو تمام حياته وشعره في المر اجع العربية والاجنبية، مكتبة الإرشاد، بغداد،. 
كان العرب أهل الكرم، وأهل الثجاعة، وأهل الحباء، و المروهة والنخوة، والوفاء بالعهد، و أهل فِطنة

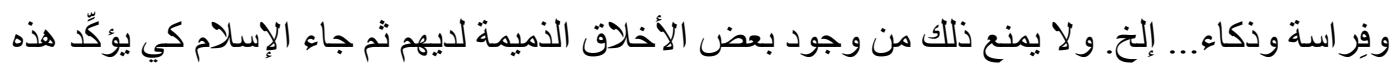

الأخلاق، ويُنْبي عليها، ويُعزِّز ها ويمدحها، كذلك جاء الإسلام بالنماذج الخُلُقية، والأو امر الأخلاقية، و النو اهي السلوكية، وبذللك يكون الإسلام قد خلق قو اعد لسلوك الإنسان و أخلاقه و أفعاله، فمنى يقم بالأو امر يَنَلِ الثواب، ومتى يُخالفِ ذللك يُعاقَب.

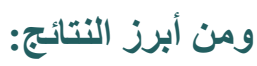

كانت المثل الأخلاقية الواردة في قصائد المديح موضع جدل وخلاف بين النقاد العرب القدامى و المحدثين من عدة جوانب أهمها: معاني الصدق و الكذب في القصيدة، تقييد فضائل المددوح و إطلاقها، أثر البداوة والحضر على القصيدة، وقد أيدت الباحثة الر أي القائل إنه يحق للثاعر في قصيدة المديح أن يذكر صفات ممدوحه

بصورة فيها مبالغة ومتكلفة فهذا يعطي للمتلقي فرصة لاكتساب الفضائل الحميدة، كذلك له حرية ذكره

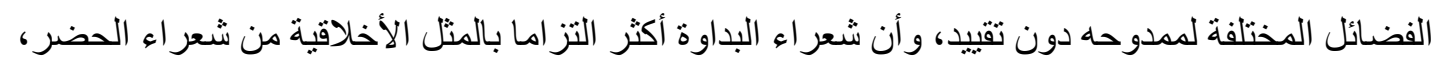
لأن البداوة وليدة الفطرة و الأخلاق الحميدة.

إنّ أكثر شعر اء العصر العباسي اعتنوا بالمديح في الثعر العربي، وبثو اصورًا حية للمثل الخلقية في مدائحهم، وأضافو ا معاني الحزم و المروءة والعفة والكرم و علو الهمة والثجاعة إلى غير ذلك من مروءات

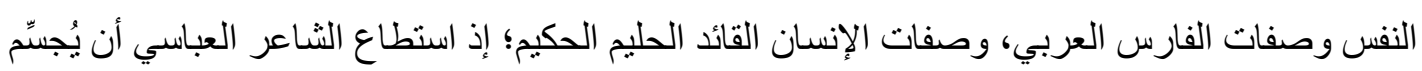
تلك المثل الخلقية في ممدوحه تجسيدًا قويَّا، و هذا نِتاج العقول الخصبة و الخيال البارع.

ازدهر المِديح على لسانِ بعض الثعر اء في تمثيل العناصر المديحيَّة القديمة وما تحويه من قيم اجتماعية ودينية عالية، وبثو ا فيها من فر ائدهم الخاصة، وأودعوا فيها عناصر جديدة استلهمو ها من البيئة الحضارية التي يعيشون فيها ومن ثقافتهم وفكر هم ومنطقهم، فنز عو ا إلى مدح الخلفاء بالتقوى و العدل، و أطالو ا في مدح القادة وشجاعتهم في المعارك و الحروب، و عند مدح الوزر اء والساسة نجد الحكمة و الحنكة و الدراية.

المصادر والمراجع

1/ البخاري، محمد (1998م)، الأدب المفرد، ط1، مكتبة المعارف للنشر و التوزيع، الرياض. 2/ الزر عي، محمد (1393-1973م)، مدارج السالكين بين منازل إيالك نعبد وإياك نستعين، ط1، دار الكتاب العربي، بيروت، لبنان. 3/ الجعفي، محمد (1422ه)، الجامع المسند الصحيح المختصر من أمور رسول اله \ـ وسننه و أيامه، ط1، دار طوق النجاة، بيروت، لبنان. 
المجلة الدولية لنشر البحوث والدراسات International Journal of Research and Studies Publishing
المجلد الثالث - الإصدار الثالث والعشرون

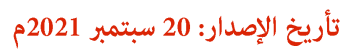

4/ الترمذي، محمد، سنن الترمذي، ط، دار إحياء التراث العربي، بيروت.

5/ النيسابوري، مسلم (1991م)، صحيح مسلح، ط1، دار إحياء الكتب العربية لعيسى البابي الحلبي. 6/ الميداني، عبد الرحمن (1999م)، الأخلاق الإسلامية وأسسها، ط5، دار القلم، دمشق. 7/ الجرجاني، علي (1983م)، التعريفات، ط1، دار الكتب العلمية بيروت، لبنان. 8/المانع، مانع (2005م)، القيم بين الإسلام والغرب در اسة تأصيلية مقارنة، ط، دار الفضيلة، الرياض. 9/ زيادة، رضوان...واخرون(2010م)، صر اع القيم بين الإسلام والغرب،ط1،دار الفكر، دمشق. 10/ شهيد، حسين (2008م)، الأخلاق في فكر أفلاطون الفلسفي، ط، مركز در اسات الكوفة 11/ الطويل، توفيق (2006)، الفلسفة الخُلقية نشأتها وتطور ها، ط، دار النهضة العربية. القاهرة 12/ رسل، برتر اند (1967م)، تاريخ الفلسفة الغربية، ط1 ، لجنة التأليف و الترجمة و النشر، القاهرة 13/ الطويل، توفيق (1953م)، مذهب النفعية العامة في فلسفة الأخلاق، ط1، مكتبة النهضة المصرية،

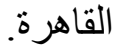

14/ حلمي، مصطفى (2004م)، الأخلاق بين الفلاسفة و علماء الإسلاح، ط1، دار الكتب العلمية، بيروت 15/ الطويل، هاني (1999م)، النظام التربوي و القيم، ط، 16/ يعقوب، أحمد، تهذيب الأخلاق وتطهير الأعراق، ط، مكتبة الثقافة الدينية، القاهرة. 17/ الساعاتي، حسن(1988م)، نسق القيم في المجتمع والتغير الاجتماعي في القيم الأخلاقية المرتبطة بعمل رجل الأمن، ط1، المركز العربي للار اسات الأمنية والتدريب، الرياض. 18/ سيد، غريب (1987م)، الإطار القيمي، ط، دار المعرفة الجامعية، الإسكندرية. 19/ أبو حطب، فؤاد (1996م)، علم النفس التربوي، ط5، الأنجلو المصرية. 20/ عوض، عباس (1991م)، في علم النفس الاجتماعي، ط، دار المعرفة الجامعية. 21/ أحمد، لطفي (1983م)، القيم والتربية، ط، دار المريخ، القاهرة. 22/ مكروم، عبد الودود (1996م)، الأصول التربوية لبناء الثخصية المسلمة، ط1، دار الفكر العربي،

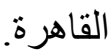
23/ الجبالي، هناء (2001م)، التربية الجمالية وتتمية القيم الأخلاقية، جامعة عين شمس. 24/ مكروم، عبد الودود (1996م)، الأصول التربوية لبناء الثخصية المسلمة، ط1، دار الفكر العربي، 25/ سورة البقرة: الآية: 143. 26/ الطبري، محمد (2001)، تفسير الطبري: جامع البيان عن تأويل آي القرآن،ط1، دار هجر للطباعة والنشر والتوزيع. 27/ عفيفي، محمد (1980م)، في أصول التربية الأصول الفلسفية في التربية، ط1، مكتبة الأنجلو

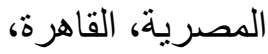
28 - سورة النحل، الآية 90. 
29/ كفافي، محمد (1989م)، تصنيف مقتر ح لبعض القيم الإسلامية، مجلة الأبحاث التربوية.

30/ قميحة، جابر (1984م)، المدخل إلى القيم الإسلامية، ط1، دار الكتب الإسلامية، القاهرة. 31/ إبر اهيم، أحمد (1982م)، الفضائل الخلقية في الإسلام، ط 1، دار العلوم للطباعة والنشر، الرياض 32/ أبو المجد، أحمد (1990م)، القيم والتحو لات الاجتماعية المعاصر، ط1، نشر مكتب المتابعة لمجلس وزر اء العمل و الثؤون الاجتماعية بالدول العربية الخليجية، المنامة. 33/ بسيوني، صلاح الدين (1990م)، القيم في الإسلام بين الذاتية والموضوعية، ط1، دار الثقافة

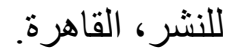
34/ نبيل سفيان، فهم الناس من خلال قيمهم، 2002، من الموقع الالكتروني التالي:  $2016 / 06 / 14$ 35/ سورة القلم، الآية 4. 36/ أنس، مالك (1985م)، الموطأ، ط، دار إحياء التراث العربي. 37/ الرازي، احمد (1999م)، معجم مقاييس اللغة، ط1، دار الكتب العلمية، بيروت، لبنان. 38/ الفيروز آبادي، مجد الدين (2005م)، القاموس المحيط، ط8، مؤسسة الرسالة للطباعة والنشر و التوزيع، بيروت، لبنان. 39/فتحي، إبر اهيم (1986م)، معجم المصطلحات الأدبية، ط1، نشر المؤسسة العربية للناشرين المتحدين، طبع التعاضدية العمالية للطباعة و النشر ، صفاقس، تونس. 40/ سورة النحل؛ الآية 30. 41 سورة الذاريات؛ الآية 48. 42/ أبي سلمى، زهير (1986م)، ديو ان زهير بن أبي سلمى، ط1، دار الكتب العلمية، بيروت. 43/ الخطفي، جرير (1986م) ديوان جرير، ديوان العرب، ط، دار بيروت، بيروت 44/ سورة النساء؛ الآية 69. 45/ المتتبي، أحمد (1983م)، ديو ان المتنبي، ط1، دار بيروت، بيروت. 56/ الخطفي، جرير (1986م) ديوان جرير، ديوان العرب، ط، دار بيروت، بيروت 47/ كلثوم، عمرو (1991م)، ديو ان عمرو بن كلثوم، ط1، دار الكتاب العربي، بيروت. 48/العبسي، جرول (1993م)، ديوان الحطيئة، ط1، دار الكتب العلمية، بيروت. 49/ اليشكري، الحارث (1991م)، ديوان الحارث بن حلزة، ط1، دار الكتاب العربي. 50/ قيس، مأمون (1437ه)، ديوان الأعثى الكبير، ط. المطبعة النموذجية، مكتبة الآداب، القاهرة. 51/ بدوي، عبده (1985م)، أبو تمام وقضية التجديد في شعره، ط1، مكتبة الثباب، القاهرة. 52/ العسكري، أبو هلال (1401م)، كتاب الصناعتين الكتابة والثعر، ط1، دار الكتابة العلمية، بيروت. 


$$
\text { الهجلة الدولية لنشر البحوث والدراسات }
$$

International Journal of Research and Studies Publishing
المجلد الثالث - الإصدار الثالث والعشرون تأريخ الإصدار: 20 سبتمبر 2021م الفالث

53/ عبد الرحمن، رائد (2010م)، ظاهرة التكسب بالثعر وتجلياتها في النقد العربي القيد، عدد1،

$$
\text { مجلة جامعة الأزهر بغزة، فلسطين. }
$$

53/ ابن قتيبة في الثعر و الشعر اء، ص30، ص33. و ابن رشيق في العدة، ج1 ص214. و أبو القاسم

محمد بن عبد الغفور الكلاعي الإشبيلي، إحكام صنعة الكلام في فنون النثر ومذاهبه في المشرق

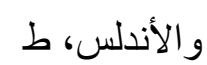

54/ الداية، محمد (1405ه)، عالم الكتب، ط، بيروت، لبنان.

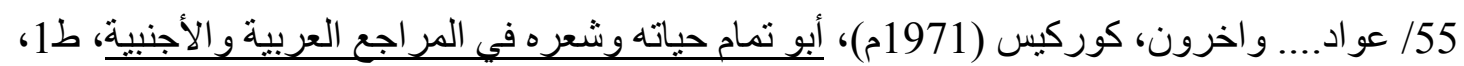
مكتبة الإرشاد، بغداد.

54/ المحاربي، عبد الله(1992م)، أبو تمام بين ناقديه قديما وحديثا، ط1، القاهرة.

Doi: doi.org/10.52133/ijrsp.v3.23.7 